\title{
Effect of Composition of Iron-Cobalt Oxide Catalyst and Process Parameters on The Hydrothermal Liquefaction of Sugarcane Bagasse
}

\author{
Gopalakrishnan Govindasamy*, Rohit Sharma, Sunu Subramanian \\ Department of Chemical Engineering, School of Engineering, University of Petroleum \& Energy Studies \\ (UPES), Dehradun, India.
}

Received: 10 th July 2019; Revised: $29^{\text {th }}$ December 2019; Accepted: 31' December 2019; Available online: $28^{\text {th }}$ February 2020; Published regularly: April 2020

\begin{abstract}
Development of catalyst with high deoxygenation activity and optimum process parameters are the key for getting the highest biooil yield with the least oxygen content by hydrothermal liquefaction. With this view, iron-cobalt oxides of $\mathrm{Co} / \mathrm{Fe}$ ratio $0.33,1.09,2.35$, and 3.52 were prepared by co-precipitation method, and characterized by XRD, BET surface area, chemical composition by EDX method, and evaluated for hydrothermal liquefaction of sugarcane bagasse in a high-pressure batch reactor under subcritical conditions using $\mathrm{CO}$ as process gas to find the optimum $\mathrm{Co} / \mathrm{Fe}$ ratio and process parameters. Optimum $\mathrm{Co} / \mathrm{Fe}$ ratio was found to be 1.09 as it gave the highest bio-oil yield of $57.6 \%$ with the least oxygen content of $10.8 \%$, attributed to the cobalt ferrite, the major phase present in it. The optimum temperature, initial $\mathrm{CO}$ pressure, water/biomass ratio, catalyst/biomass ratio and reaction time for the highest oil yield with the least oxygen content were found to be $250^{\circ} \mathrm{C}, 45$ bar, $28,0.4$, and 120 min, respectively. From the effect of reaction time, it was found that much of the hydrolysis of lignocellulose to water soluble oxygenates, its deoxygenation to bio-oil and its deoxygenation to low oxygen containing bio-oil took place in initial $15 \mathrm{~min}, 15$ to $60 \mathrm{~min}$, and from 30 to $120 \mathrm{~min}$, respectively. Total oil yield (\%) was lower by $21 \%$ and \% oxygen in total oil was higher by $9.9 \%$ for spent catalyst compared to fresh catalyst indicating the erosion in the deoxygenation activity of catalyst and thus need for improving its hydrothermal stability. Copyright (c) 2020 BCREC Group. All rights reserved
\end{abstract}

Keywords: Hydrothermal liquefaction; Sugarcane bagasse; Bio-oil; Catalyst; Thermochemical conversion

How to Cite: Govindasamy, G., Sharma, R., Subramanian, S. (2020). Effect of Composition of IronCobalt Oxide Catalyst and Process Parameters on The Hydrothermal Liquefaction of Sugarcane Bagasse. Bulletin of Chemical Reaction Engineering \& Catalysis, 15(1), 186-198 (doi:10.9767/bcrec.15.1.5385.186-198)

Permalink/DOI: https://doi.org/10.9767/bcrec.15.1.5385.186-198

\section{Introduction}

Ever increasing automobile population increased the demand for gasoline and diesel, derived from petroleum resulting in its fast depletion and on the other hand automobile exhaust

* Corresponding Author.

E-mail: gopalakrishnan@ddn.upes.ac.in (G. Gopalakrishnan);

Telp: +91 135 2770137, Fax: +91-135-2776090 became an important source of air pollution and global warming. Thus, biofuels are one of the important solutions to these twin issues of sustainability as they are derived from biomass, a renewable source and carbon neutral from the life cycle view point. Among the biofuels, bioethanol a substitute for gasoline demands carbohydrates as biomass feedstock employing biochemical conversion [1,2]. Biodiesel, a partial substi- 
tute for diesel demands lipids as biomass feed stock using chemical [3] or biochemical conversion [4] involving transesterification. In contrast bio-oil a potential substitute for both gasoline and diesel after upgradation is produced from wide range of biomass employing thermochemical conversions namely pyrolysis [5,6], hydropyrolysis [7] and hydrous pyrolysis or hydrothermal liquefaction (HTL) [8]. Among them, HTL has generated significant interest as it has several advantages over other thermochemical conversions [9], notably its ability to handle wet biomass. HTL is regarded as mimic of natural process of formation of petroleum [10] but taking only minutes to hours unlike natural process taking millennium. The bio-oil, gas, char and aqueous phase containing dissolved oxygen rich water-soluble oxygenates (WSO) are the products of HTL of which bio-oil is the energy product. Several homogeneous and heterogeneous catalysts explored for HTL to maximize the bio-oil yield was reviewed by Kim et al. [11] and Yeh et al. [12]. The homogeneous catalysts mainly alkali was reported to give high conversion but low bio-oil yield with high oxygen content [13], besides being corrosive and difficult to recover and recycle [14]. Bio-oil containing high oxygen content lead to low heating value, high acidity, instability and immiscibility with auto fuels derived from petroleum [15]. The keys for HTL yielding higher amount of bio-oil with the least oxygen content in a single step were reported to be the appropriate heterogeneous catalyst having deep deoxygenation activity and optimum process conditions [16]. Maag et al. [17] studied the HTL of food waste and reported that heterogeneous $\mathrm{CeZrO}_{\mathrm{x}}$ catalyst yielded higher amount of biooil compared to homogeneous $\mathrm{Na}_{2} \mathrm{CO}_{3}$ catalyst due to the reduction in the WSO yield by $50 \%$. Recently Amar et al. [18] reported that the HTL of pinewood at $300{ }^{\circ} \mathrm{C}$ with $(\mathrm{Co}, \mathrm{Ni})$ - Fe oxide nanoparticles synthesized by sol-gel technique as catalyst yielded higher amount of oil compared to non-catalytic HTL. For large scale commercialization of HTL, need for developing reusable heterogeneous catalysts that minimizes the yield of WSO by deoxygenating it into bio-oil for improved energy recovery from biomass and reduction in treatment cost of aqueous phase was emphasized by several authors [19-23].

HTL of sugarcane bagasse to low oxygen containing bio-oil over Co-, Mo-, Fe-, and Tisubstituted MCM-41, their oxides and mixed metal oxides of Fe-Mo, Fe-Co, Co-Mo, and Ti-Zr in the presence of $\mathrm{CO}$ as process gas was reported [24]. Among the catalysts studied, Fe-Co oxide $(\mathrm{Co} / \mathrm{Fe}$ atomic ratio of 1.09$)$ was found to yield the highest amount of oil with the least oxygen content because the iron oxide enabled the CO to undergo the water gas shift (WGS) reaction, yielding hydrogen radicals in situ which is more reactive than molecular $\mathrm{H}_{2}$. Cobalt oxide could have facilitated the deoxygenation of the refractory oxygenates such as furans, phenols and aryl ethers, possibly involving hydrogenation, dehydration and hydrodeoxygenation (HDN) [14] with the help of the hydrogen generated, the mechanism of the same was reviewed by Furimsky [25], which depends on experimental conditions and feed composition. Iron oxide was also reported to have decarboxylation activity as it converted the palmitic acid to pentadecane by HTL [26] and this could possibly be another reason for low oxygen content of oil.

Hence in this study, Fe-Co mixed metal oxides of different $\mathrm{Co} / \mathrm{Fe}$ ratio were prepared and evaluated for the catalytic HTL of sugarcane bagasse under specific process conditions to find the optimum $\mathrm{Co} / \mathrm{Fe}$ ratio for the highest oil yield with the least oxygen content. For the catalyst with optimum $\mathrm{Co} / \mathrm{Fe}$ ratio, effect of temperature, initial $\mathrm{CO}$ pressure, reaction time, biomass/catalyst ratio, water/biomass ratio were studied and their optimum values for the highest oil yield with the least oxygen content were reported. Spent catalyst recovered after burning of the char from the residue left after the fresh catalytic run was evaluated for the HTL of sugarcane bagasse under identical conditions at which fresh catalyst was studied and their performance compared.

\section{Materials and Methods}

\subsection{Materials}

Sugarcane bagasse was kindly supplied by Doiwala Sugar Company Limited, Doiwala, Uttarakhand, India. Cobaltous chloride hexahydrate (98\%), ferrous chloride tetrahydrate (99\%), and aqueous ammonia (25\%) of Merck were used for the preparation of catalysts. Diethyl ether, ethyl acetate and acetone of LR grade from SRL were used for the extraction of oils from the product mixture. Carbon monoxide of UHP grade supplied by Gupta industrial Gases was used as the process gas.

\subsection{Catalyst Preparation and Characterization}

Iron-Cobalt mixed metal oxides of varying $\mathrm{Co} / \mathrm{Fe}$ atomic ratios were prepared by coprecipitation method. Aqueous solutions of ferrous chloride and cobaltous chloride were pre- 
pared separately and mixed together in varying propositions to get initial $\mathrm{Co} / \mathrm{Fe}$ atomic ratio of $0.5,1,2$, and 4 . Aqueous ammonia solution (11\%) was added under stirring and allowed to age for $1 \mathrm{~h}$. The precipitates formed were separated by filtration, followed by drying in airoven at $120^{\circ} \mathrm{C}$ for $5 \mathrm{~h}$ and calcined in electrical muffle furnace at $500^{\circ} \mathrm{C}$ for $4 \mathrm{~h}$.

The calcined catalysts were characterized by powder XRD in the $2 \theta$ range of 10 to $80^{\circ}$ with Bruker D8 advance diffractometer, using nickel-filtered $\mathrm{Cu}-\mathrm{K} \alpha$ radiation $(\lambda=1.54 \AA)$ and liquid nitrogen-cooled germanium solid-state detector equipped with crystallography open database (REV89244 2013.10.11). Chemical composition of the catalysts was studied using SEM- Zeiss EVO-40 EP with Bruker liquid nitrogen free X-Flash 4010 Energy Dispersive Xray micro-analyzer. The surface area and pore volume of the catalysts were determined by nitrogen adsorption at $-196{ }^{\circ} \mathrm{C}$ using Micromeritics ASAP-2020 with built-in BJH algorithm software.

\subsection{Hydrothermal Liquefaction Studies}

2.3.1 Feedstock preparation and characterization

Sugarcane bagasse was milled, screened to get particles with diameters smaller than 0.3 $\mathrm{mm}$, dried in an air-oven at $115^{\circ} \mathrm{C}$ for $24 \mathrm{~h}$ and stored in a desiccator at room temperature which was used as the biomass feed stock. Its proximate analysis was performed according to ASTM D 3172-73 (1984) and elemental composition (CHNSO) was determined using Thermo Flash $2000 \mathrm{CHNS} / \mathrm{O}$ organic elemental analyzer calibrated with 2,5-Bis(5-tert-butylbenzoxazol-2-yl) thiophene as a standard.

\subsubsection{Effect of catalyst composition on HTL}

Effect of catalyst composition on the HTL of sugarcane bagasse was carried out in a $170 \mathrm{~mL}$ stainless-steel high-pressure reactor (BR 100, Berghof) with a magnetic stirrer cum heater and a tubular furnace around the reactor [24]. In a typical reaction run, $2.5 \mathrm{~g}$ of sugarcane ba-

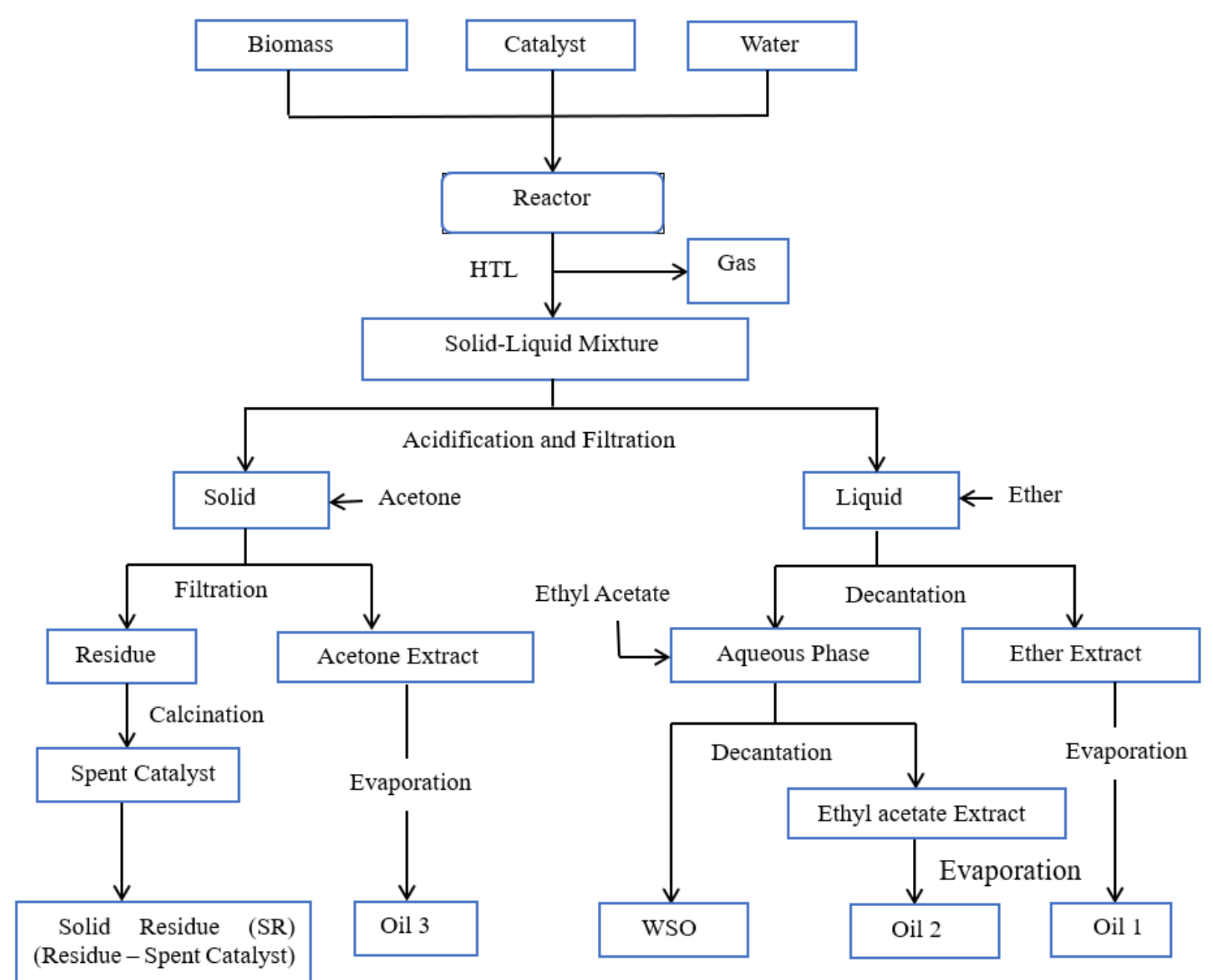

Figure 1. Process Flow Diagram of hydrothermal liquefaction of sugarcane bagasse 
gasse and $70 \mathrm{~mL}$ of distilled water were taken into the reactor and $1 \mathrm{~g}$ of catalyst was added, similar to the proposition reported by Minowa et al. [27]. Then the reactor was closed, purged with $\mathrm{CO}$ and then filled with $\mathrm{CO}$, till the initial pressure reached 45 bar and then gas inlet was closed and placed over the magnetic stirrer cum heater. Contents of the reactor were agitated by magnetic stirring at $1400 \mathrm{rpm}$. The reactor was heated to $250{ }^{\circ} \mathrm{C}$ at the rate of 20 ${ }^{\circ} \mathrm{C} / \mathrm{min}$ and maintained for $120 \mathrm{~min}$ while the pressure increased from 45 to 90 bar.

After the reaction time of $120 \mathrm{~min}$, the reactor was cooled to room temperature and the gaseous products were vented into atmosphere through the CO incinerator. The remaining solid-liquid product mixture was separated into Oil 1 (ether extract of liquid), Oil 2 (ethyl acetate extract of liquid), Water Soluble Oxygenates (WSO), Oil 3 (acetone extract of solid) and Residue by following the procedure reported by Karagoz et al. [13]. Since heterogeneous catalyst was used in the present study, residue obtained included the spent catalyst and char.

Table 1. Proximate and ultimate analysis of sugarcane bagasse.

\begin{tabular}{clc}
\hline \multicolumn{2}{c}{ Parameters } & Content \\
\hline \multirow{2}{*}{$\begin{array}{c}\text { Proximate Analysis } \\
\text { in Weight \% }\end{array}$} & Volatisture content & 60.18 \\
(on air dried basis) & Ash content & 32.49 \\
& Fixed Carbon & 1.7 \\
& Carbon & 5.63 \\
\hline \multirow{2}{*}{ Ultimate Analysis } & Oxygen & 31.98 \\
in Weight\% & Hydrogen & 17.04 \\
(on dry basis) & Nitrogen & 0.79 \\
& Sulphur & 0 \\
\hline
\end{tabular}

Hence the residue was burnt at $500{ }^{\circ} \mathrm{C}$ for $1 / 2 \mathrm{~h}$ to get the weight of spent catalyst and then yield of Solid Residue (SR) was obtained by subtracting the weight of spent catalyst from the Residue (Figure 1). Elemental analyses of the products were performed in Thermo Flash 2000 CHNS/O Organic Elemental Analyzer. Iron-cobalt oxide catalyst giving the highest \% Total Oil Yield and the lowest \% Oxygen in Total Oil was identified as optimum catalyst.

\subsubsection{Effect of process parameters on HTL}

Effect of reaction time on HTL of sugarcane bagasse was studied for the optimum catalyst by varying the reaction time viz $15,30,60$ and $120 \mathrm{~min}$, while keeping rest of the parameters as mentioned in the above section. Similarly, the effect of temperature (viz 225, 250 and 275 ${ }^{\circ} \mathrm{C}$ ), initial $\mathrm{CO}$ pressure (viz 25, 45 and $60 \mathrm{bar}$ ), catalyst/biomass ratio (viz $0,0.2,0.4$ and 0.6 ) and water/biomass ratio (viz 15, 28, 40) were studied for the optimum catalyst. The spent catalyst obtained after calcining the residue at $500{ }^{\circ} \mathrm{C}$ for $3 \mathrm{~h}$ was evaluated for the HTL of sugarcane bagasse under identical conditions at which fresh catalyst was studied, as described in Section 2.3.2. Two runs were carried out for each reaction run and the values reported were average of them, and the maximum deviation between the yields of products obtained in the duplicate runs were within $3 \%$.

\subsubsection{Calculation Method}

The \% Conversion, \% Yield of the products, $\%$ Yield of Total Oil and \% Oxygen in Total Oil were calculated as per the equations reported earlier [24].

Table 2. Catalyst Characterization.

\begin{tabular}{|c|c|c|c|c|c|}
\hline Catalyst & $\begin{array}{c}\text { Initial } \\
\mathrm{Co} / \mathrm{Fe} \\
\text { atomic } \\
\text { ratio }\end{array}$ & $\begin{array}{l}\mathrm{Co} / \mathrm{Fe} \text { atomic } \\
\text { ratio of catalyst } \\
\text { (EDX Analysis) }\end{array}$ & Relative Abundance of Phases & $\begin{array}{c}\text { BET } \\
\text { Surface } \\
\text { Area } \\
\left(\mathrm{m}^{2} / \mathrm{g}\right)\end{array}$ & $\begin{array}{c}\text { BJH } \\
\text { Pore } \\
\text { Volume } \\
\left(\mathrm{cm}^{3} / \mathrm{g}\right)\end{array}$ \\
\hline MOFC-1 & 0.5 & 0.33 & $\begin{array}{l}\text { Hematite (Hexagonal) }>\text { Lepidocrocite } \\
\left(\text { Orthorhombic) }>\mathrm{Co}_{3} \mathrm{O}_{4}(\text { Cubic })>\text { Cobalt }\right. \\
\text { ferrite }(\text { Cubic })\end{array}$ & 176 & 0.20 \\
\hline MOFC-2 & 1 & 1.09 & $\begin{array}{l}\text { Cobalt ferrite }(\text { Cubic })>\mathrm{Co}_{3} \mathrm{O}_{4}(\text { Cubic })> \\
\text { Lepidocrocite (Orthorhombic) }>\text { Magnet- } \\
\text { ite }(\text { Cubic })\end{array}$ & 137 & 0.26 \\
\hline MOFC-3 & 2 & 2.35 & $\begin{array}{l}\mathrm{Co}_{3} \mathrm{O}_{4}(\mathrm{Cubic})>\text { Lepidocrocite } \\
\text { (Orthorhombic) }>\text { Cobalt ferrite (Cubic) }\end{array}$ & 154 & 0.21 \\
\hline MOFC-4 & 4 & 3.52 & $\begin{array}{l}\text { Lepidocrocite (Orthorhombic) }>\text { Cobalt } \\
\text { ferrite }(\text { Cubic })>\mathrm{Co}_{3} \mathrm{O}_{4}(\text { Cubic })\end{array}$ & 163 & 0.21 \\
\hline
\end{tabular}




\section{Results and Discussion}

\subsection{Feedstock Characteristics}

The results of proximate and ultimate analysis of sugarcane bagasse are presented in Table 1 and found to be similar to reported values [28].

\subsection{Catalyst Characterization}

Chemical composition of the catalysts analyzed by EDX, relative abundance of phases present in the catalyst arrived by XRD, BET surface area, and BJH desorption pore volume determined by nitrogen adsorption are presented in Table 2. Co/Fe ratio of catalysts MOFC- 1 and MOFC-4 were less than the initial $\mathrm{Co} / \mathrm{Fe}$ ratio of the solutions from which they were obtained due to the presence of higher proportion of iron rich phases as evidenced from XRD result. On the other hand, the $\mathrm{Co} / \mathrm{Fe}$ ratio of cata- lysts MOFC-2 and MOFC-3 were higher than the initial $\mathrm{Co} / \mathrm{Fe}$ ratio of the solutions from which they were formed due to the presence of higher proportion of cobalt containing phases in them. BET model, the most widely used for the determination of surface area gives total surface area mainly accounting meso and macropores while the BJH method, the most widely used for pore volume mainly accounts for the meso pore volume [29]. This explains why MOFC- 1 and MOFC- 4 have shown higher BET surface area and lower BJH pore volume than the other catalysts, since hematite and lepidocrocite, the major phases respectively present in them were reported to undergo textural modifications [30], forming macropores upon calcination. The lowest BET surface area and the highest BJH pore volume of MOFC-2 containing cobalt ferrite as the major phase could be attributed to its retention of mesopo-

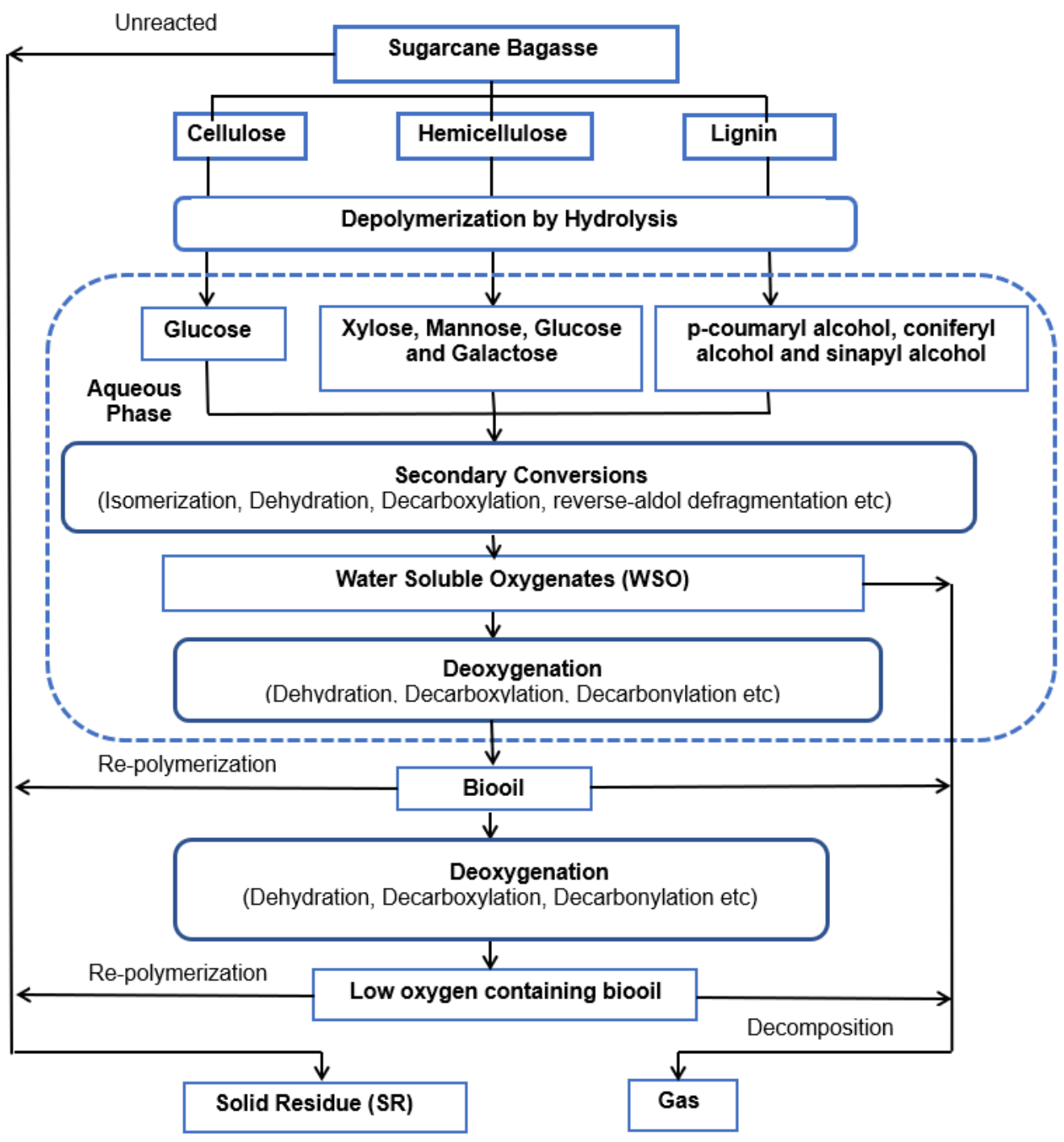

Figure 2. Reaction pathways of HTL of sugarcane bagasse 
rosity without undergoing any textural modification to form macropores upon calcination.

\subsection{Hydrothermal Liquefaction of Sugarcane Bagasse}

The reaction pathways of catalytic hydrothermal liquefaction of sugarcane bagasse to low oxygen containing bio-oil is presented in Figure 2. Initial phase of HTL is the depolymerization of lignocellulose to phenols and sugars by hydrolysis which along with the products formed by their secondary conversions together constitute the water soluble oxygenates (WSO). These reactions are mainly catalyzed by the $\mathrm{H}^{+}$and $\mathrm{OH}^{-}$furnished by the hot compressed water due to its high ionic product [8]. WSO undergoes deoxygenation to yield water immiscible bio-oil which undergoes further deoxygenation to low oxygen containing bio-oil both of which depends on the deoxygenation activity of the catalyst [24] and process conditions [22]. WSO and bio-oil may either undergo repolymerization to yield char which together with the unreacted sugarcane bagasse constitute the solid residue (SR) or decomposition to yield gas [9].

\subsection{Effect of $\mathrm{Co} / \mathrm{Fe}$ Atomic Ratio of Catalyst on} HTL

Effect of $\mathrm{Co} / \mathrm{Fe}$ atomic ratio of catalyst on the conversion, yield of products and oxygen content of oils are presented in Figure 3. It was found that the iron-cobalt catalyst (MOFC-2) with $\mathrm{Co} / \mathrm{Fe}$ ratio of 1.09 gave the highest \% Total Oil Yield of $57.6 \%$ and the least \%Oxygen in Total Oil of $10.8 \%$ and hence this was the optimum $\mathrm{Co} / \mathrm{Fe}$ ratio for the highest oil yield with the least oxygen content.

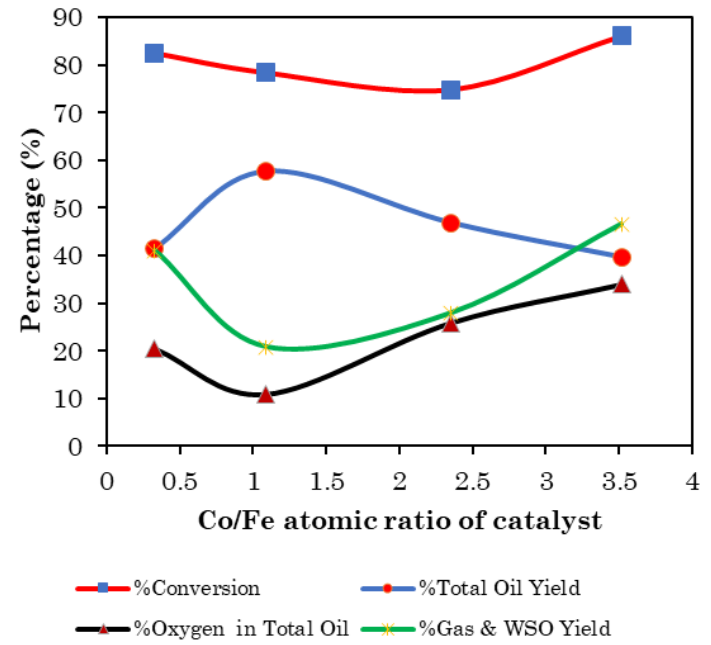

At $\mathrm{Co} / \mathrm{Fe}$ atomic ratio of 0.33 (MOFC- 1 ), \%Conversion was 82.5 which was almost same as that of $83 \%$ obtained in non-catalytic HTL, but \%Total Oil Yield was 6.3\% higher, \%Oxygen in Total Oil was $11.1 \%$ lower and \%Gas and WSO Yield was $6.9 \%$ less than noncatalytic HTL. This indicated that MOFC-1 containing hematite as major phase has shown moderate deoxygenation activity. The deoxygenation activity was due to WGS reaction whose mechanism involved alternatingly hematite $\left(\mathrm{Fe}_{2} \mathrm{O}_{3}\right)$ being reduced by $\mathrm{CO}$ to magnetite $\left(\mathrm{Fe}_{3} \mathrm{O}_{4}\right)$ and oxidation of magnetite formed to hematite by $\mathrm{H}_{2} \mathrm{O}$ forming hydrogen in situ and thus the WGS activity of the catalyst was related to easy reduction of $\mathrm{Fe}^{3+}$ to $\mathrm{Fe}^{2+}$ [31]. Overreduction of the magnetite to lower oxide (wustite, $\mathrm{FeO}$ ) and metallic iron was reportedly to be avoided as they were active catalysts for methanation [32]. Increase in $\mathrm{Co} / \mathrm{Fe}$ atomic ratio from 0.33 to 1.09 (MOFC-2), decreased the \%Conversion by $4.1 \%$ but steeply increased the \%Total Oil Yield by $16.1 \%$ due to the sharp decline in the \%Gas and WSO yield by $20.3 \%$ and decreased the \%Oxygen in Total Oil by $9.6 \%$. These observations indicated the strongest deoxygenation activity by MOFC-2 as inferred from the reaction pathways of HTL (Figure 2). This could be attributed to the cobalt ferrite, the major phase present in it (Table 2) as it was reported that at $\mathrm{Co} / \mathrm{Fe}$ atomic ratio of 1 , cobalt formed cobalt ferrite $\left(\mathrm{CoO} \cdot \mathrm{Fe}_{2} \mathrm{O}_{3}\right)$ and the presence of cobalt in octahedral sites made the hematite easier to get reduced to magnetite and also prevented its further reduction [33].

With an increase in $\mathrm{Co} / \mathrm{Fe}$ atomic ratio from 1.09 to 2.35 (MOFC-3), \%Total Oil Yield decreased by $10.7 \%$ due to increase in \%SR and $\%$ Gas and WSO Yield by 3.6 and $10.7 \%$, respec-

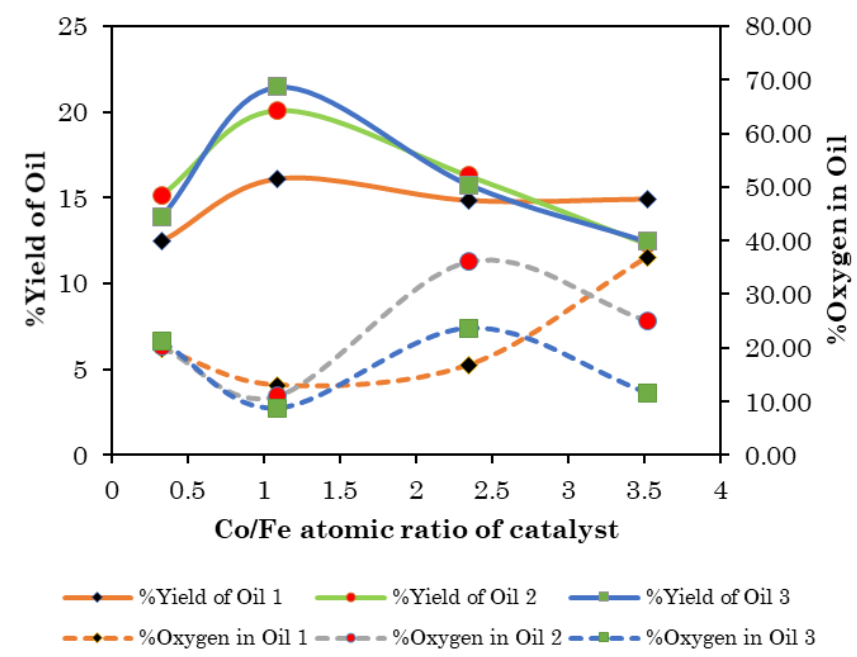

Figure 3. Effect of $\mathrm{Co} / \mathrm{Fe}$ atomic ratio on the catalytic activity. 
tively and increased the \%Oxygen in Total Oil by $15 \%$. Since the pressure of the reactor remained steady during the reaction, \%Gas and WSO Yield could be taken as \%WSO Yield. Major iron oxide phase present in MOFC-3 was lepidocrocite $(\gamma-\mathrm{FeO}(\mathrm{OH}))$, consisted of iron(III) oxide octahedral layers bonded by hydroxide layers through hydrogen bonding [30] might not be easy to get reduced by $\mathrm{CO}$ and thus not active for WGS reaction. As the result, required hydrogen was not made available accounting for decreased deoxygenation and the major phase $\mathrm{Co}_{3} \mathrm{O}_{4}$ present would have increased the repolymerization of unsaturates formed. Further increase to 3.52 (MOFC-4), decreased the \%Total Oil Yield to the least of 39.7 despite an increase in the \%Conversion to the maximum of 86.1, due to the increase in \%Gas and WSO Yield to the maximum of $46.6 \%$, which was only $1.4 \%$ less than non-catalytic HTL. \%Oxygen in Total Oil also increased to the maximum of $34 \%$ which was even higher than non-catalytic HTL by $2.5 \%$. Higher yield of WSO and oxygen content of oil indicated the lowest deoxygenation activity of MOFC-4, again because lepidocrocite was the major phase present and $\mathrm{Co}_{3} \mathrm{O}_{4}$ was only a minor phase and hence less repolymerization of unsaturates accounting for the least \%SR and hence the highest \%Conversion.

With increase in $\mathrm{Co} / \mathrm{Fe}$ ratio from 0.33 to 1.09, \% Yield of Oil 1, 2, and 3 reached the maximum and \%Oxygen in Oil 1, 2, and 3 reached the minimum in accordance with the trend of \%Total Oil Yield and \%Oxygen in Total oil (Figure 3). The oil 1 and 3 were reported to contain mainly phenols [28], refractory oxygenates while oil 2 comprised of aliphatic oxygenates which were relatively easy to deoxygenate, thus reaffirmed the fact that cobalt ferrite was the most active phase for deoxygenation. With further increase to 2.35 , \%Yield of Oil 1,2 , and 3 decreased while \%Oxygen in Oil 1, 2, and 3 increased in accordance with the trend of \%Total Oil Yield and \%Oxygen in Total Oil, a negative confirmation of cobalt ferrite as the most active for deoxygenation. Interestingly, with an increase from 2.35 to 3.52 , \%Yield of Oil 1 increased by $0.8 \%$, despite an increase in \%Oxygen in Oil 1 to the maximum of 36.9 , which was even $1.5 \%$ higher than non-catalytic HTL. On the other hand, \%Yield of Oil 2 and 3 decreased by 4 and $3.3 \%$ respectively and \%Oxygen in Oil 2 and 3 decreased by 11 and $12 \%$ respectively which was in contrary to the trend of oil 1. This could be possibly because cobalt ferrite, the second abundant phase in MOFC-4 $(\mathrm{Co} / \mathrm{Fe}=3.52)$ was sufficient enough to deoxygenate aliphatic oxygenates in oil 2 and high molecular weight phenols in oil 3 , but not for low molecular weight phenols in oil 1.

3.5 Effect of Process Parameters on The Performance of Optimum Catalyst MOFC-2

\subsubsection{Effect of reaction time}

Effect of reaction time on the \%Conversion, \%Total Oil Yield, \%Oxygen in Total Oil, \%Gas and WSO Yield, \%Yield of Oils and \%Oxygen in Oils are shown in Figure 4 for the optimum catalyst MOFC- 2 . The $66 \%$ conversion of sugarcane bagasse took place in the first $15 \mathrm{~min}$ itself and gradually increased to $78.4 \%$ with an increase in reaction time to $120 \mathrm{~min}$. Under similar conditions but without catalyst, hemicellulose of the woody and herbaceous biomass was completely hydrolyzed in 2 min at $230{ }^{\circ} \mathrm{C}$ [34], cellulose was $100 \%$ hydrolyzed in 2 min at $280{ }^{\circ} \mathrm{C}$ [35] and $40 \%$ of commercial lignin was
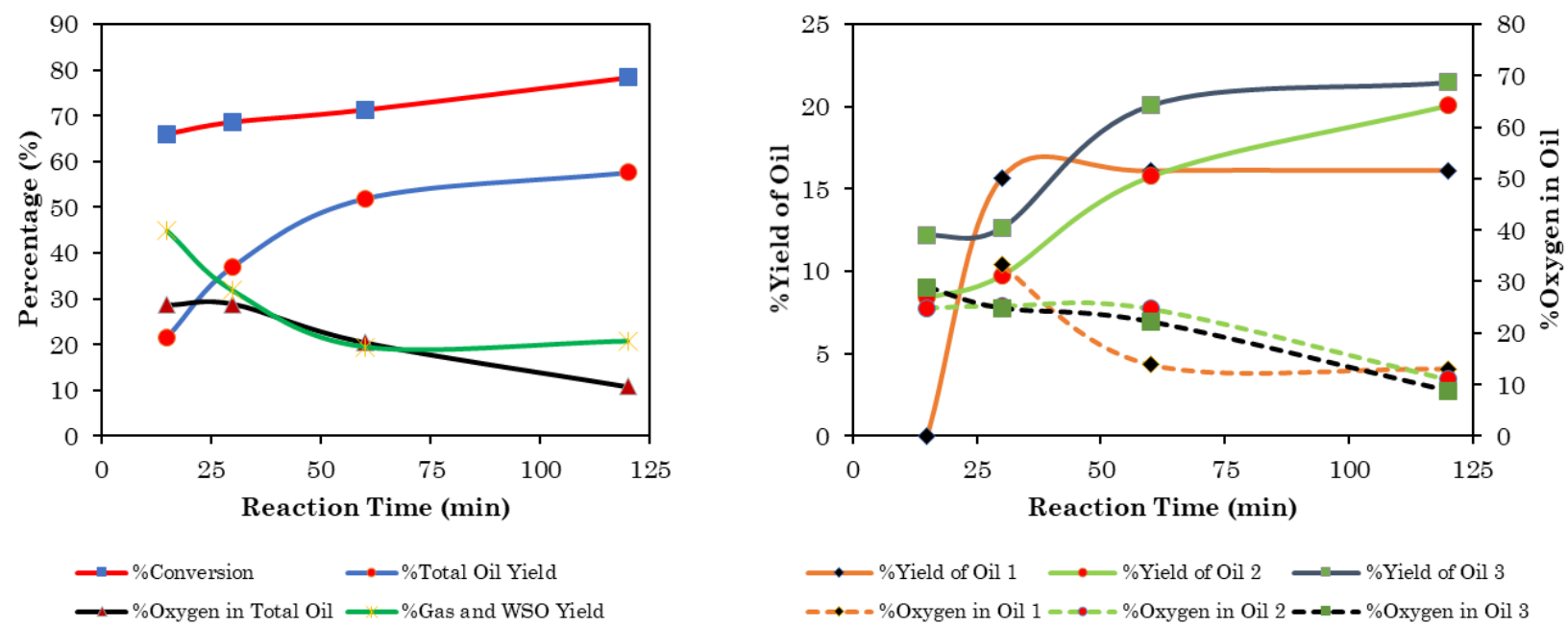

Figure 4. Effect of reaction time 
hydrolyzed after $15 \mathrm{~min}$ at $280{ }^{\circ} \mathrm{C}$ [36]. As the lignin content of sugarcane bagasse was reported to be around $28 \%$ [37], it could be concluded that much of the conversion achieved up to 15 min in the present study was due to the depolymerization of cellulose and hemicellulose of sugarcane bagasse while the gradual increase in \%Conversion observed with increase in reaction time could be attributed to the progressive depolymerization of lignin part of sugarcane bagasse by hydrolysis.

An increase in reaction time from 15 to 60 min, sharply increased the \%Total Oil Yield by $30.3 \%$ despite only a $5.3 \%$ increase in \%Conversion was essentially due to sharp decrease in $\%$ Gas and WSO Yield by $25.3 \%$, as the WSO was deoxygenated to oil. With the doubling of reaction time from 60 to $120 \mathrm{~min}$, \%Total Oil Yield increased only by $5.7 \%$ mainly due to $7.1 \%$ increase in \%Conversion mainly of lignin while the \%Gas and WSO Yield remained the same. \%Oxygen in Total Oil remained almost same up to $30 \mathrm{~min}$ and then decreased with further increase in reaction time to $120 \mathrm{~min}$. Much of the \%Conversion obtained in initial 15 min, sharp increase in \%Total Oil Yield from 15 to $60 \mathrm{~min}$ with corresponding sharp decrease in \%Gas and WSO Yield and decrease in \%Oxygen in Total Oil from 30 to 120 min, suggested that there was a discrete kinetic regime operated namely, hydrolysis of lignocellulose to WSO, deoxygenation of WSO to bio-oil and its further deoxygenation to low oxygen containing bio-oil, with very little overlapping.

There was no Oil 1 up to $15 \mathrm{~min}$ and appeared only after $30 \mathrm{~min}$ and the amount remained the same with further increase in reaction time to 120 min whereas the \%Yield of Oil 2 and 3 have increased sharply from 30 to 120 min. Thus the increase in \%Total Oil Yield from 15 to $30 \mathrm{~min}$ was almost due to Oil 1 while from 30 to $120 \mathrm{~min}$ was almost due to Oil 2 and 3. Oil 1 was reported to be comprised of mainly compounds of low boiling points based on the analysis of molecular composition and carbon number distribution [13,36] and thus possibly needed more time for its formation from the secondary conversion of compounds of high boiling points present in Oil 2 and 3 . \%Oxygen in Oil 1 decreased from 30 to $60 \mathrm{~min}$ sharply and remained almost same thereafter thus main contributor to the decrease in \%Oxygen in Total Oil for this period. \%Oxygen in Oil 2 and 3 did not change much up to $60 \mathrm{~min}$ and then decreased sharply with further increase in reaction time to $120 \mathrm{~min}$ contributing to the decrease in \%Oxygen in Total Oil from 60 to $120 \mathrm{~min}$.

\subsubsection{Effect of temperature}

Increase in temperature from 225 to $275^{\circ} \mathrm{C}$ increased the \%Conversion continuously from 75.7 to 83.9. On the other hand, \%Total Oil Yield increased from $41.8 \%$ at 225 to $57.6 \%$ at $250{ }^{\circ} \mathrm{C}$ but decreased to $36.3 \%$ at $275{ }^{\circ} \mathrm{C}$ and the same trend was shown by the yield of all the three oils though the increase was more for Oil 2 and 3 at $250{ }^{\circ} \mathrm{C}$ (Figure 5). This was in accordance with several authors [38,39], but the exact temperature at which maximum oil yield occurred varied with nature of biomass, catalyst and other process parameters either due to oil components re-polymerized to SR or decomposed to gas [22]. In the present study, the decrease in \% Total Oil Yield from 250 to $275{ }^{\circ} \mathrm{C}$ was attributed to decomposition of oil components to gas as evidenced from decrease
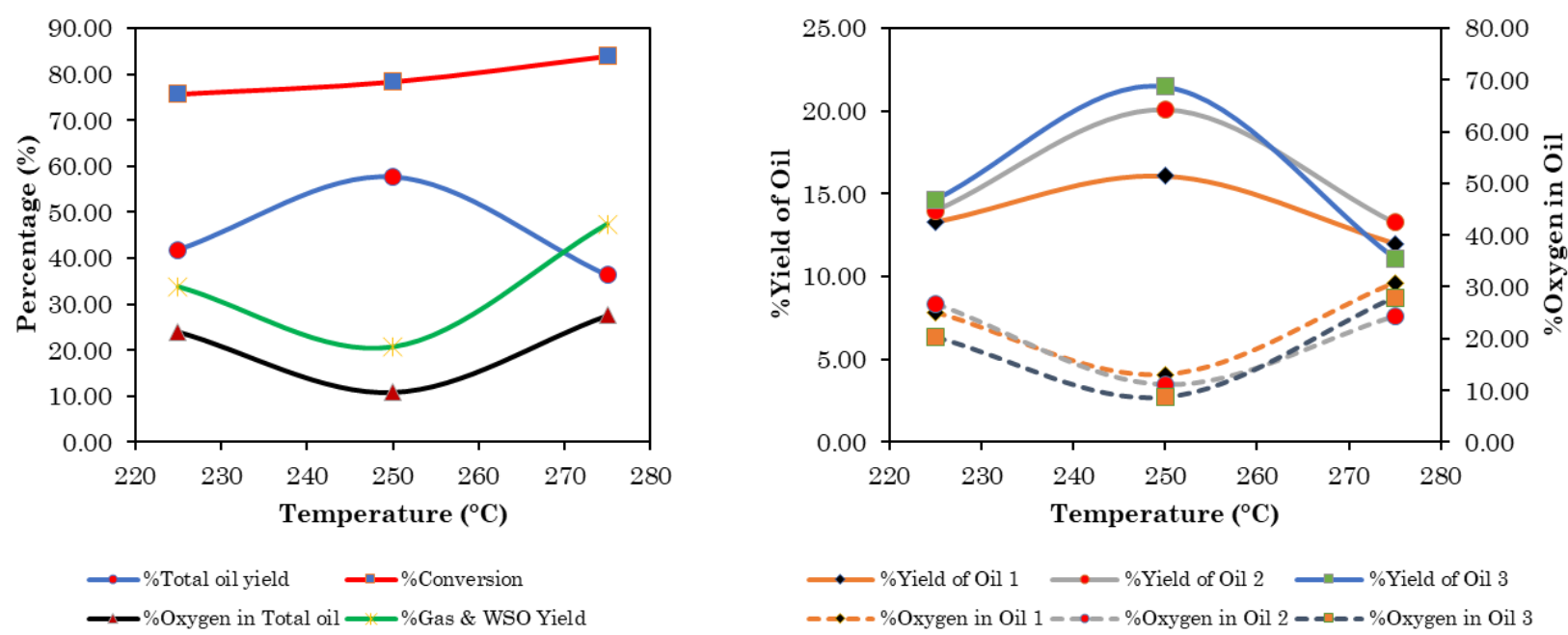

Figure 5. Effect of temperature 
in \%Yield of SR and increase in \%Gas and WSO yield which was due to increase in gas yield in this case as inferred from gradual increase in pressure to above 90 bar at $275^{\circ} \mathrm{C}$. Similarly, \%Oxygen in Total Oil decreased from 24 to $10.8 \%$ with increase in temperature from 225 to $250{ }^{\circ} \mathrm{C}$ but increased to $27.5 \%$ with the further increase in temperature to $275^{\circ} \mathrm{C}$ and same trend was shown by \%Oxygen in Oils 1,2 and 3 as well. From these observations, it could be concluded that $250{ }^{\circ} \mathrm{C}$ was the optimum temperature for deoxygenation whereas decomposition was favored at $275^{\circ} \mathrm{C}$.

\subsubsection{Effect of initial CO pressure}

Increase in initial pressure of $\mathrm{CO}$ from 25 to 45 bar increased the \%Conversion and \%Total Oil Yield while decreased the \%Gas and WSO Yield and \%Oxygen in Total Oil (Figure 6). With further increase to 60 bar decreased the
\%Conversion and \%Total Oil Yield while increased the \% Gas and WSO Yield and \%Oxygen in Total Oil which may be attributed to increase in the local solvent density by high pressure and the formation of cage effect on the $\mathrm{C}-\mathrm{C}$ bond which inhibited its cleavage [22]. Similar trend was shown by the \%Yield of Oil 1,2 and 3 and \%Oxygen in Oil 1,2 and 3, though the increase in yield was more for Oil 2 and 3 with increase in pressure from 25 to 45 bar.

\subsubsection{Effect of Water/Biomass (W/B) ratio}

Increase in W/B ratio from 15 to 40 increased the \%Conversion from 77.3 to $82.8 \%$ (Figure 7) as the water played the role of reaction medium, reactant and catalyst in HTL. Under subcritical conditions, water has low dielectric constant making it non-polar, hence improved miscibility with biomass and has
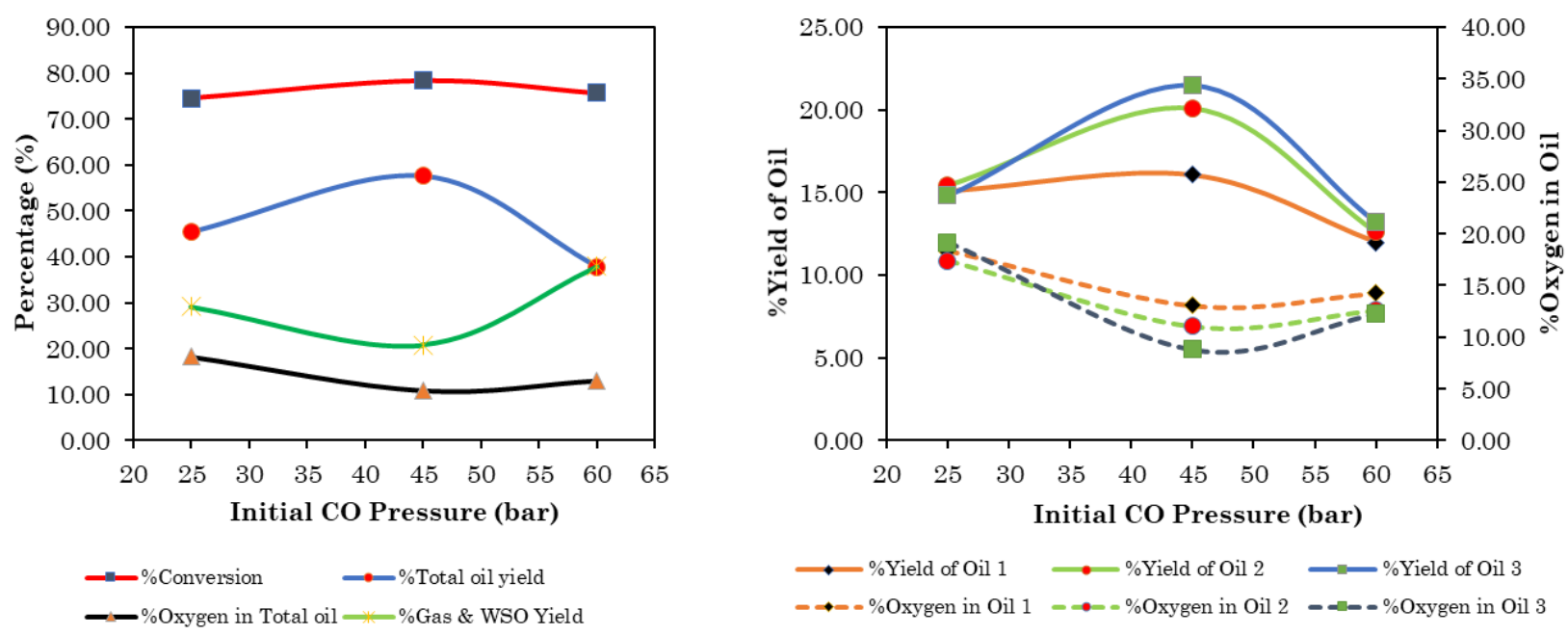

$\rightarrow--\%$ Oxygen in Oil $1 \ldots$ \% Oxygen in Oil $2 \ldots--\infty$ Oxygen in Oil 3

Figure 6. Effect of initial CO pressure
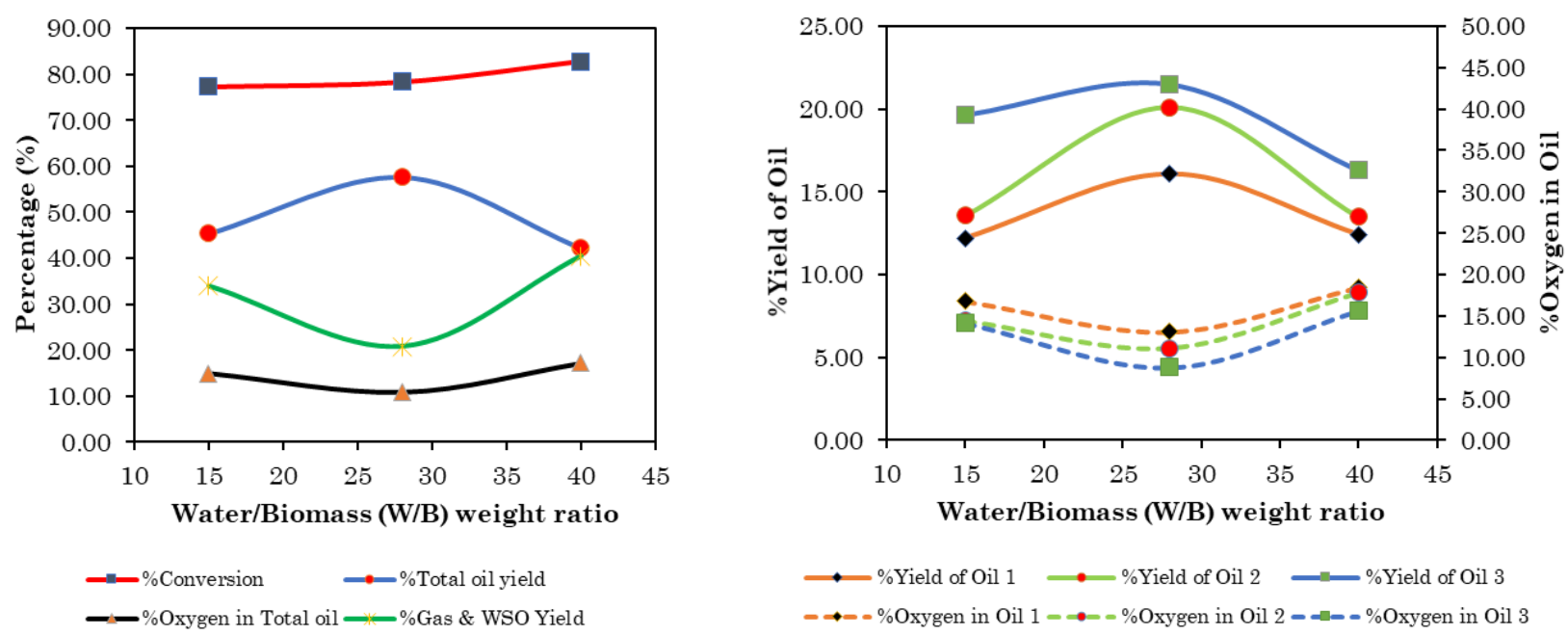

Figure 7. Effect of water/biomass (W/B) weight ratio 
high ionic product thus enhancing the acidbase catalyzed hydrolysis of lignocellulose [8], together accounted for the increased conversion. On the other hand, with the increase in W/B ratio from 15 to 28 , \%Total Oil Yield increased from 45.4 to $57.6 \%$ due to decrease in $\%$ Gas and WSO Yield from 34 to $20.8 \%$ and with further increase to 40 , \%Total Oil Yield decreased to $42.2 \%$ due to increase in \%Gas and WSO Yield to $40.5 \%$. Similarly, \%Oxygen in Total Oil decreased from 15 to $10.8 \%$ with the increase in W/B ratio from 15 to 28 and further increase to 40 , it increased to $17.1 \%$. From these observations it could be concluded that the optimum W/B ratio to get maximum yield of oil with least oxygen content was 28. Beyond the optimum W/B ratio, WSOs were stabilized by aqueous phase and their further deoxygenation by dehydration to oil got hindered by the excess water as governed by Le-Chatelier's principle. Effect of W/B ratio on the \%Yield of Oil 1,2 and 3 and \%Oxygen in Oil 1,2 and 3 followed the same trend of \%Total Oil Yield and \%Oxygen in Total Oil, but the effect was more pronounced for Oil 2 and Oil 3 (Figure 7).

\subsubsection{Effect of Catalyst/Biomass (C/B) Ratio}

For non-catalytic HTL of sugarcane bagasse (C/B of 0 ), \%Conversion was the highest (83\%), \%Total Oil Yield was the lowest (35.2\%), \%Oxygen in Total Oil was the highest (31.5\%) and
\%Gas and WSO Yield was the highest (48\%) compared to HTL in the presence of the catalyst (Figure 8). This only reaffirmed the fact that the depolymerization of lignocellulose responsible for the conversion of sugarcane bagasse was independent of catalyst [8]. With the increase in $\mathrm{C} / \mathrm{B}$ ratio from 0 to 0.6 , \%Conversion decreased from 83 to $75.7 \%$ as the \%Yield of SR increased which might be due to the repolymerization of WSO and oil components to char (Figure 2.).

Whereas with the increase in $\mathrm{C} / \mathrm{B}$ ratio from 0 to 0.4 , \% Total Oil Yield increased by $22.4 \%$ despite a decrease in \%Conversion and \%Oxygen in Total Oil by 5 and $20.7 \%$, respectively, due to steep decrease in \%Gas and WSO Yield by $27.2 \%$. This was because the increased amount of catalyst increased the deoxygenation of WSO to oil and its subsequent deoxygenation to low oxygen containing oil, reaffirmed the fact that deoxygenation activity of catalyst was responsible for the oil yield and its oxygen content [24]. Increase in \%Yield of Oil 1 was maximum for the increase in $\mathrm{C} / \mathrm{B}$ ratio from 0 to 0.2 , increase in \%Yield of Oil 2 was maximum from 0.2 to 0.4 while the increase in \%Yield of Oil 3 was observed continuously from 0 to 0.4 and the highest among three oils (Figure 8). Decrease in \%Oxygen in Oil 1 was maximum when $\mathrm{C} / \mathrm{B}$ ratio was increased from 0 to 0.2 coincided with its increase in yield
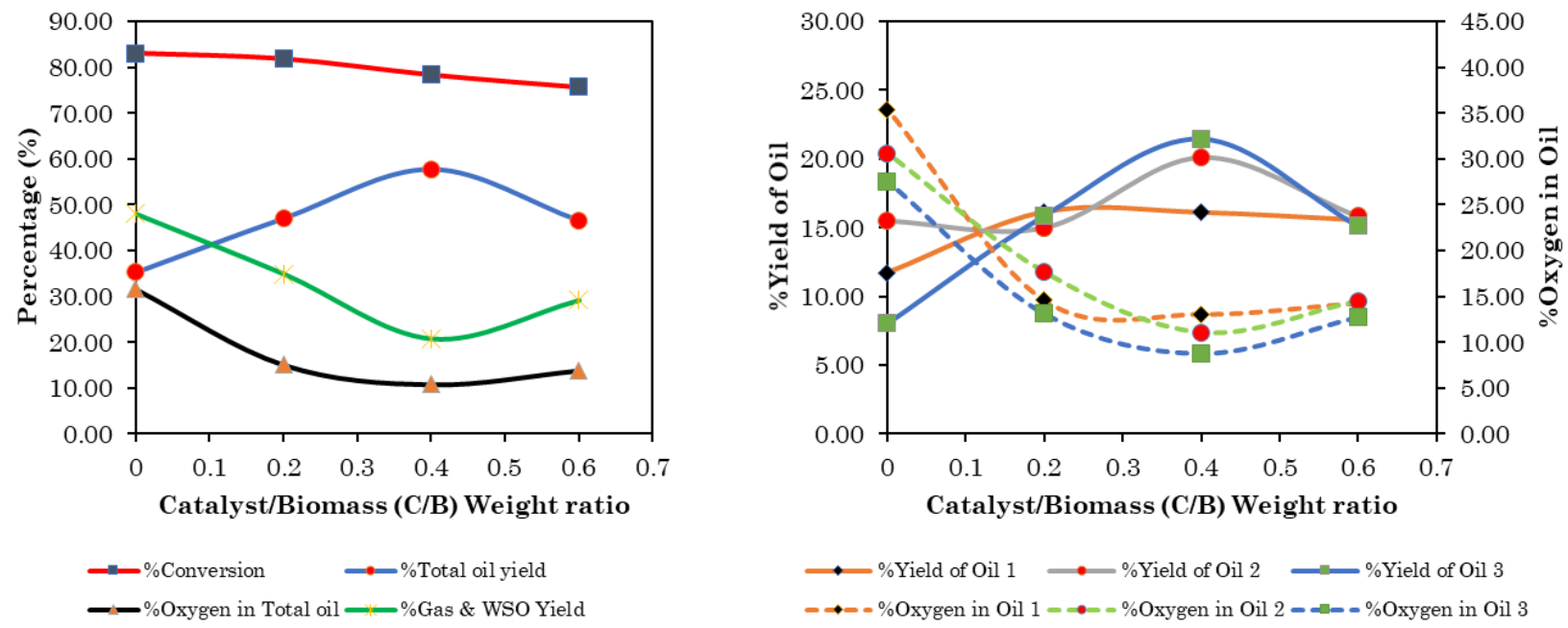

Figure 8. Effect of catalyst/biomass (C/B) weight ratio.

Table 3. Catalytic performance of fresh and spent MOFC-2 catalyst.

\begin{tabular}{ccccccccc}
\hline Optimum Catalyst & $\%$ & \multicolumn{4}{c}{ \%Yield of Products } & \%Total & \%Oxygen \\
\cline { 3 - 6 } MOFC-2 & Conversion & SR & Gas \& WSO & Oil 1 & Oil 2 & Oil 3 & Oil Yield & in Total Oil \\
\hline Fresh & 78.4 & 21.6 & 20.8 & 16.0 & 20.1 & 21.5 & 57.6 & 10.8 \\
Spent & 62.8 & 37.2 & 26.3 & 12.6 & 12.0 & 12.0 & 36.6 & 20.7 \\
\hline
\end{tabular}


whereas decrease in \%Oxygen in Oil 2 and 3 were observed continuously from 0 to 0.4 , thus the overall decrease in \%Oxygen in Total Oil also came from different oils at different $\mathrm{C} / \mathrm{B}$ ratios.

With further increase in $\mathrm{C} / \mathrm{B}$ ratio to 0.6 , $\%$ Total Oil Yield decreased by $11 \%$ due to decrease in the yield of all the three oils, reaching the same levels, while the \%Oxygen in Total Oil increased by $3 \%$ due to increase in the $\%$ Oxygen in all the three oils. The decrease in \%Total Oil Yield was due to both the decomposition and repolymerization of oil components to gas and solid residue respectively as indicated by increase in \%SR by 2.7 and \% Gas and WSO Yield by $8.4 \%$, which was mainly from the increased gas yield as inferred from the increase in pressure to slightly higher than 90 bar. Thus, the optimum $\mathrm{C} / \mathrm{B}$ ratio for maximum oil yield containing the least oxygen content was found to be 0.4 .

3.5.6 Comparison of activity of fresh and spent catalyst for HTL

The \%Conversion, \%Yield of products, \%Total Oil Yield and \%Oxygen in Total Oil for fresh and spent catalyst are presented in Table 3 . The \%Conversion and \%Total Oil Yield given by spent catalyst were lower by 15.6 and $21 \%$ respectively compared to fresh catalyst. This might be due to the repolymerization of oil components to char rather than due to unconverted sugarcane bagasse, since the \%Conversion for non-catalytic HTL of sugarcane bagasse itself was 83\% (Figure 8). Further, \%Oxygen in Total Oil and \%Gas and WSO Yield were higher by $9.9 \%$ and $5.5 \%$, respectively for spent catalyst compared to fresh catalyst. These observations indicated that there was a loss of deoxygenation activity and increased polymerization activity of the catalyst which might be due to hydration and phase transformation occurred for oxides under the hydrothermal condition [40]. Developing stable catalysts under hydrothermal conditions is the key challenge for the development of economical processes for biofuel production [41] and isomorphic substitution of Fe and Co into hydrothermally stable support, such as: siliceous zeolites [42], may overcome this problem which will be the future studies.

\section{Conclusions}

Among the iron-cobalt oxide catalyst with $\mathrm{Co} / \mathrm{Fe}$ ratio $0.33,1.09,2.35$ and 3.52 studied for HTL of sugarcane bagasse under subcritical condition, optimum $\mathrm{Co} / \mathrm{Fe}$ ratio was found to be
1.09 , giving maximum oil yield containing the least oxygen which may be attributed to cobalt ferrite the major phase present in it. Within the range of values of process parameters studied, the optimum values of temperature, initial CO pressure, reaction time, water/biomass ratio and catalyst/biomass ratio for maximum oil yield with the least oxygen content were 250 ${ }^{\circ} \mathrm{C}, 45$ bar, $120 \mathrm{~min}, 28$ and 0.4 , respectively. The effect of various process parameters on the yield of oil 2 and 3 was more pronounced compared to yield of oil 1. From the effect of reaction time, it could be concluded that there was a discrete kinetic regime operated namely, hydrolysis of lignocellulose to WSO, deoxygenation of WSO to bio-oil and deoxygenation of biooil to low oxygen containing bio-oil with very little overlapping. From the decreased \%Total Oil Yield and the increased \%Oxygen in Total Oil and \%Gas and WSO Yield for spent catalyst compared to fresh catalyst, it could be concluded that there was a loss of deoxygenation activity due to hydrothermal condition to which the catalyst was exposed in the previous catalytic run. Hence, there is a need to improve the hydrothermal stability of iron-cobalt oxide catalyst despite its high oil yield containing less oxygen with fresh catalyst. Therefore, synthesis and evaluation of hierarchical Fe-CoZSM-12 as catalyst will be taken up in the next studies.

\section{Acknowledgement}

This work was supported by the Ministry of New and Renewable Energy, Government of India (Grant number F.No.7/184/2013-B F) and the authors sincerely thank them for their financial support.

\section{References}

[1] Balat, M., Balat, H. (2009). Recent trends in global production and utilization of bioethanol fuel. Applied Energy, 86, 2273-2282.

[2] Saini, J.K., Reetu, S.R., Tewari, L. (2015). Lignocellulosic agriculture wastes as biomass feedstocks for second-generation bioethanol production: Concepts and recent developments. 3 Biotech, 5, 337-353.

[3] Thanh, L.T., Kenji, O., Luu, V., Yasuaki, M. (2012). Catalytic technologies for biodiesel fuel production and utilization of glycerol: A review. Catalysts, 2, 191-222.

[4] Kumari, A., Mahapatra, P., Garlapati, V.L., Banerjee, R. (2009). Enzymatic transesterification of Jatropha oil. Biotechnology for Biofuels, 2, 1-7. 
[5] Mohan, D., Pittman, C.U., Steele, P.H. (2006). Pyrolysis of Wood/Biomass for Bio-oil: A Critical Review. Energy \& Fuels, 20, 848-889.

[6] Vamvuka, D. (2011). Bio-oil, solid and gaseous biofuels from biomass pyrolysis processesAn overview. International Journal of Energy Research, 35, 835-862.

[7] Onay, O., Gaines, A.F., Kockar, O.M., Adams, M., Tyagi, T.R., Snape, C.E. (2006). Comparison of the generation of oil by the extraction and the hydropyrolysis of biomass. Fuel, 85, $382-392$.

[8] Toor, S.S., Rosendahl, L., Rudolf, A. (2011). Hydrothermal liquefaction of biomass: a review of subcritical water technologies. Energy, $36,2328-2342$.

[9] Gollakota, A.R.K., Kishore, N., Gu, S. (2018). A review on hydrothermal liquefaction of biomass. Renewable and Sustainable Energy Reviews, 81, 1378-1392.

[10] Lewan, M.D., Winters, J.C., McDonald, J.H. (1979). Generation of oil-like pyrolyzates from organic-rich shales. Science, 203, 897-899.

[11] Kim, J-Y., Lee, H.W., Lee, S.M., Jae, J., Park, Y-K. (2019). Overview of the recent advances in lignocellulose liquefaction for producing biofuels, bio-based materials and chemicals. Bioresource Technology, 279, 373-384.

[12] Yeh, T.M., Dickinson, J.G., Franck, A., Linic, S., Thompson, L.T.Jr., Savage, P.E. (2013). Hydrothermal catalytic production of fuels and chemicals from aquatic biomass. Journal of Chemical Technology \& Biotechnology, 88, 13-24.

[13] Karagoz, S., Bhaskar, T., Muto, A., Sakata, Y., Oshiki, T., Kishimoto, T. (2005). Lowtemperature catalytic hydrothermal treatment of wood biomass: analysis of liquid products. Chemical Engineering Journal, 108, 127-137.

[14] Cheng, S., Lin, W., Rabnawaz, M. (2018). Catalytic liquefaction of pine sawdust and in-situ hydrogenation of biocrude over bifunctional Co-Zn/HZSM-5 catalysts. Fuel, 223, 252-260.

[15] Wang, W., Yang, Y., Luo, H., Liu, W. (2010). Effect of additive (Co, La) for Ni-Mo-B amorphous catalyst and its hydrodeoxygenation properties. Catalysis Communications, 11, 803-807.

[16] Zhou, C.H., Xia, X., Lin, X.C., Tong, X.D., Beltramini, J. (2011). Catalytic conversion of lignocellulosic biomass to fine chemicals and fuels. Chemical Society Reviews, 40, 55885617.

[17] Maag, A.R., Paulsen, A.D., Amundsen, T.J., Yelvington, P.E., Tompsett, G.A., Timko, M.T. (2018). Catalytic hydrothermal liquefaction of food waste using CeZrOx. Energies, 11(3), 564.

[18] Amar, V.S., Shende, A., Shende, R.V. (2019). BTMO catalyzed hydrothermal liquefaction of lignocellulosic biomass. TechConnect Briefs, ISBN 978-0-9988782-8-7: 195-198.

[19] Zhu, Y., Biddy, M.J., Jones, S.B., Elliott, D.C., Schmidt, A.J. (2014). Techno-economic analysis of liquid fuel production from woody biomass via hydrothermal liquefaction (HTL) and upgrading. Applied Energy, 129, 384394.

[20] Kumar, M., Oyedun, O.A., Kumar, A. (2018). A review on the current status of various hydrothermal technologies on biomass feedstock. Renewable and Sustainable Energy Reviews, 81, 1742-1770.

[21] Dimitriadis, A., Bezergianni, S. (2017). Hydrothermal liquefaction of various biomass and waste feedstocks for biocrude production: A state of the art review. Renewable and Sustainable Energy Reviews, 68, 113-125.

[22] Xue, Y., Chen, H., Zhao, W., Yang, C., Ma, P., Han, S. (2016). A review on the operating conditions of producing bio-oil from hydrothermal liquefaction of biomass. International Journal of Energy Research, 40, 865-877.

[23] Cao, L., Zhang, C., Chen, H., Tsang, D.C.W., Luo, G., Zhang, S., Chen, J. (2017). Hydrothermal liquefaction of agricultural and forestry wastes: state-of-the art review and future prospects. Bioresource Technology, 245, 1184-1193.

[24] Govindasamy, G., Sharma, R., Subramanian, S. (2018). Studies on the effect of heterogeneous catalysts on the hydrothermal liquefaction of sugarcane bagasse to low-oxygencontaining bio-oil. Biofuels, 10(5), 665-675.

[25] Furimsky, E. (2000). Review Catalytic hydrodeoxygenation. Applied Catalysis A: General, 199, 147-190.

[26] Bian, J., Zhang, Q., Zhang, P., Feng, L., Li, C. (2017). Supported $\mathrm{Fe}_{2} \mathrm{O}_{3}$ nanoparticles for catalytic upgrading of microalgae hydrothermal liquefaction derived bio-oil. Catalysis Today, 293-294, 159-166.

[27] Minowa, T., Zhen, F., Ogi, T. (1998). Cellulose decomposition in hot-compressed water with alkali or nickel catalyst. Journal of Supercritical Fluids, 13, 253-259.

[28] Schuchardt, U., Matos, F.A.P. (1982). Liquefaction of sugar cane bagasse with formate and water. Fuel, 61, 106-110.

[29] Leofanti, G., Padovan, M., Tozzola, G., Venturelli, B. (1998). Surface area and pore texture of catalysts. Catalysis Today, 41, 207 219. 
[30] Cornejo, J., Hermosin, M.C. (1988). Evolution of porosity and changes in heat treated lepidocrocite. Journal of Soil Science, 9, 265274.

[31] Zhu, M., Wachs, I.E. (2016). Iron-based catalysts for the high temperature water-gas shift (HT-WGS) reaction: A review. ACS Catalysis, 6(2), 722-732.

[32] Rhodes, C., Hutchings, G.J., Ward, A.M. (1995). Water-gas shift reaction: finding the mechanistic boundary. Catalysis Today, 23, 43-58.

[33] Khan, A., Smirniotis, P.G. (2008). Relationship between temperature-programmed reduction profile and activity of modified ferritebased catalysts for WGS reaction. Journal of Molecular Catalysis A: Chemical, 280, 43-51

[34] Mok, W.S.L., Antal, M.J.Jr. (1992). Uncatalyzed solvolysis of whole biomass hemicellulose by hot compressed liquid water. Industrial \& Engineering Chemistry Research, 31, 1157-1161.

[35] Rogalinski, T., Liu, K., Albrecht, T., Brunner, G. (2008). Hydrolysis kinetics of biopolymers in subcritical water. Journal of Supercritical Fluids, 46, 335-341.

[36] Karagoz, S., Bhaskar, T., Muto, A., Sakata, Y. (2005). Comparative studies of oil compositions produced from sawdust, rice husk, lignin and cellulose by hydrothermal treatment. Fuel, 84, 875-884.
[37] Qi, G., Peng, F., Xiong, L., Lin, X., Huang, C., Li, H., Chen, X., Chen, X. (2017). Extraction and characterization of wax from sugarcane bagasse and the enzymatic hydrolysis of dewaxed sugarcane bagasse. Preparative Biochemistry and Biotechnology, 47(3), 276-281.

[38] Malins, K. (2017). Production of bio-oil via hydrothermal liquefaction of birch sawdust. Energy Conversion and Management, 144, 243251.

[39] Zhu, Z., Rosendahl, L., Toor, S.S., Yu, D., Chen, G. (2015). Hydrothermal liquefaction of barley straw to bio-crude oil: Effects of reaction temperature and aqueous phase recirculation. Applied Energy, 137, 183-192.

[40] Gardner, D.W., Huo, J., Hoff, T.C., Johnson, R.L., Shanks, B.H., Tessonnier, J.P. (2015). Insights into the hydrothermal stability of ZSM-5 under relevant biomass Conversion reaction Conditions. ACS Catalysis, 5, 4418-4422.

[41] Bell, A.T., Gates, B.C., Ray, D. (2007). Basic Research Needs: Catalysis for Energy, Report from the U.S. Department of Energy, (PNNL17214), Office of Basic Energy Sciences Workshop, Bethesda, Maryland.

[42] Prodinger, S., Derewinski, M.A., Vjunov, A., Burton, S.D., Arslan, I., Lercher, J.A. (2016). Improving stability of zeolites in aqueous phase via selective removal of structural defects. Journal of the American Chemical Society, 138(13), 4408-4415. 